nation broncho-pneumonia is considered permissible only when extension of the disease from the bronchial terminations to the peribronchial tissues can be demonstrated. It was found that the lungs of persons dead of other diseases and not suffering from pneumonia contained bacterial mixtures similar to those found in cases of pneumonia, and in these also the diplococcus pneumoniæ preponderated. Further, bacteria, some pathogenic, were found in the lungs of domestic animals, such as pigs, oxen, horses, calves, not suffering from pneumonia.

From these observations it seems fair to infer that the normal lungs of healthy individuals always contain pathogenic bacteria, whose mere presence is not sufficient to set up disease. In addition there must be some traumatic or other disturbing influence. It was found experimentally that simple injection into the trachea of animals of the bacteria found in pneumonic lungs is not alone sufficient to induce pneumonia. When, however, irritating substances were injected, either previously or simultaneously or subsequently, pneumonia resulted. Injection of the latter alone also proved capable of causing pneumonia, and exposure to cold likewise was followed by the development of pneumonia of lobar, fibrinous and mycotic type. These two forms of pneumonia owe their origin to injury of the pulmonary structure, in consequence of which the microörganisms already present undergo multiplication and acquire pathogenic properties. The harmful influence of cold depends in all probability upon the induction of an acute intense hyperemia of the lungs. The presence of pathogenic bacteria in the normal lungs of healthy persons helps to make clear the occurrence of the so-called mixed or secondary infection of tuberculosis.

\section{ON THE TREATMENT OF TYPHOID FEVER.}

$$
\text { BY E. VIKO, M.A., M.D. }
$$$$
\text { PARK CITY, UTAH. }
$$

In 1870 Selmi discovered the ptomains, and later Bouchard pointed out the rôle the ptomains play in infectious diseases; knowing the lesions of typhoid fever and its cause many physicians then came to the conclusion that intestinal antiseptics should be employed in this disease. Silver nitrate was employed in 1860 by Joseph Bell of Glasgow, and later by William Pepper of Philadelphia, who treated 100 consecutive cases without a death. As early as 1883, Da Costa employed thymol with good success; ever since thymol has gained in favor. Naphthalin was praised by Rosbach as an abortive in typhoid fever; Kraemer in 1886, Wilcox in 1887, Sehwald in 1889 and Wolff of Philadelphia in 1891 confirmed Rosbach's observations. Mules (British Medical Journal, Feb. 27,1892 ) reported that many cases of typhoid could be aborted with naphthol. Salol, calomel, beta-naphthol, turpentine, and mineral acids have received their share of praise.

According to my experience, under proper diet and by the use of intestinal antiseptics, the death rate in typhoid fever ought to be almost nil. I have treated several thousand cases and have tried thymol, salol, beta-naphthol, calomel, copper arsenite, guaiacol and mineral acids, either combined or separate. My preference is for thymol, salol, beta-naphthol and calomel. Under their administration the attack can be aborted or shortened, or it will run a mild course. lielapses are apt to occur if the medicine is stopped too soon. I order the medicine used for at least two weeks after the fever has abated. The patient is ordered to drink all the water desired. The water is boiled, cooled and aërated; ice is allowed; milk, if it agrees, is ordered; beef tea and soft-boiled eggs, mild stimulation during convalescence. If the stomach is irritable, rectal feeding of milk and beef tea is resorted to when necessary. My prescriptions generally read:

(For an adult.)

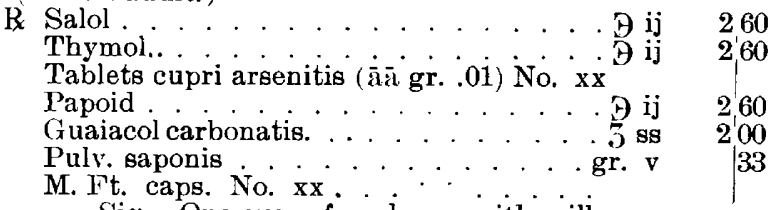

Sig.-One every four hours with milk.

(For children.)

B Beta.naphthol, dissolved in heated oil..gr. xxiv

Ol. amygdal. dulcis, dis. in heated oil. . 3 ss

Pulv. acaciæe.

Glycerini.

Aq., q.s ad

M. Ft. emulsio.

m. $j$

q.s.

亏 $\mathrm{sB}$

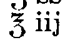

Sig.-One teaspoonful every four hours with milk for 3-year-old child.

The bowels are moved once or twice a day with calomel and soda. At this place, I desire to express my opinion as regards acetanilid. Most authorities condemn it; in large doses it will certainly do harm. In small doses (4 grs. every three or four hours) I have found it very beneficial; it keeps the temperature inside safe limits and lessens tissue oxidation. It produces sweat, which is certainly desirable. The pulse becomes slower and stronger (action analogous to digitalis). My prescription reads:

B Salol, acetanilid M. Ft. pulv. No, xv..

$\overline{\operatorname{ta}} 3 \mathrm{j}$

Sig.-One every three or four hours when fever goes above 102 degrees $\mathrm{F}$.

Under the above detailed treatment sordes on the tongue never appear, and seldom delirium; hemorrhage from the bowels is rare; death rate is almost nil.

$A$ word as to the Woodbridge method. On reading his article in the Journal for July 10, 1897, one is left with the impression that Woodbridge has made a new discovery. His treatment is not new (see short historic sketch at the beginning of this article). The only new and novel thing about it is a variety of tablets and capsules. As to novelty they are certainly admirable; as to practicability they are a nuisance. The drugs used are all good and $\mathrm{I}$ do not doubt but that he will have good success with them, but the doses are too small and the intervals between doses are too short, thereby unnecessarily disturbing the patient too often; the purging is also excessive. Larger doses, longer intervals between doses and less purging will produce just as good results if not better. The sentence: "The declaration that typhoid is a curable malady has been for years and is yet nearly always greeted with such acrimonious and vituperative dissent," etc., is unwarranted, as the writings on intestinal antisepsis are quite extensive and date back to 1870 (see authorities mentioned and also Hare's "System of Practical Therapeutics," 1892).

Permit me to report a curious instance with reference to the cause of an outbreak of typhoid last fall in four families who live outside of town near the mines at a place called the Alliance tunnel. They receive their water supply from a small creek. The water is conducted first through two barrels as a reservoir and thence 
to their houses. Eleven became sick with typhoid; the youngest was 11 months old, the oldest about 35 years; in some the temperature was normal at from eloven to fifteen days, in others about twenty-one days; in one in thirty-six days and in another about forty days, counting the relapses. All got well. The average duration of the disease was fourteen or fifteen days. Undoubtedly several more cases would have occurred in those families had they not been instructed to boil their drinking water. Later the barrels used as reservoirs were cleaned out and three more or less decomposed squirrels were found in the barrels.

Some two or three years ago this town used to be a regular hotbed for typhoid fever. The cause was in the water supply. The fever would be most severe in December and January; at that time the usual water supply was insufficient and water from a stream polluted with human excrement was turned into the city reserroirs.

\section{THE USE AND THE ABUSE OF THE} BICYCLE.

Read before the Central Wisconsin Medical Society, at Evansville,

BY JAMES MILLS, M.S., M.D. JANESVILLE, WIS.

The world is on wheels; doctors and ministers, lawyers and teachers, husbands and wives, kings and th queens, old and young, rich and poor, are all equal in cycling; and all must pedal, sweat and breathe dust alike. In this they share the same joys and sorrows. Cars and steamboats are wholesome affairs, so far as equalizing our outward conditions is concerned; but your true leveler in locomotion is the bicycle.

In this "age of inventions," what the telegraph and the telephone do for thought and voice, the bicycle does for the body. It is a machine with the power of impulsion induced by the muscular motion of the rider's limbs; it is a horse and buggy combined; costs less than either and fattens on air. It enables the doctor to outride microbes, and catch ozone on the wing. It puts him in prime condition for visiting his patients, and is an amazing economizer of his time and energy. It suggests to him the importance of caution, courage, courtesy and self-reliance; and particularly of "looking before leaping." Like the moth that circles about the flame, he will find the danger of "scorching"; and possibly like it, take warning from the sad mishaps of others who often outride him.

It is for the general public interest, that legitimate and orderly cycling should be encouraged. The use of the bicycle for traveling, especially in the country, has in it the germ of the solution of the improvement of public highways. When wheelmen have become sufficiently banded together to compel the maintenance of well-paved streets and good roads and the safe use thereof by them, there will be a heavy falling off in the tribute paid by the people to elevated-track magnates and traction barons, who now control our street and railway conveyances, and tax the people for the proud privilege of getting to and from their daily labors.

Beyond all these, there is the certainty of a higher physical standard for the race in the universal employment of a vehicle which insures to its users fresh air and healthful bodily exercise. I believe that the bicycle, properly used, is of very great value to a large number of people who would not otherwise indulge in sufficient outdoor activity.

The majority of accidents to cyclers in the cities are the results of inexperience in riding and the carelessness of the drivers of horses. In Germany and some other European countries, this fact is recognized; and before a novice is allowed to go out upon the public highways, he or she is required to give an exhibition of proficiency before duly appointed examiners. We venture to assert that this would obviate many of the present dangers which are universally admitted to need attention, and would thereby appreciably reduce the number of street accidents.

The subject of bicycling for women is beginning to attract the notice of medical writers. Dr. Robert L. Dickinson of Brooklyn, N. Y., is among the foremost who have given the subject attention. Some French, English, German and American gynecologists have given their opinions upon the subject, and the greater number of them agree that, as a rule, where this exercise is not carried to excess, it is a beneficial one.

In it we seem to have found, at Jast, a form of an open air muscular work, which induces women to spend many hours away from close rooms and indoor tasks. It exercises and strengthens a large number of muscles of the body, far more than is generally supposed. Ask the beginner or the expert, how much bodily balance is required. Ask the woman who sits upright, holding tightly to the handle bars as she works up a grade, how much arm-and-shoulder pull there is in it

Since bicycling is one of the few popular physical exercises that attract women, it will, under properly prescribed conditions undoubtedly show itself capable of large results as an agent in curing pelvic disorders. There is no problem that troubles the physician more than the prescription for proper physical exercise by women in view of her disabilities and the disadvantages under which she has suffered in attempts to obtain pleasurable and beneficial muscular action. It seems hardly too much to say that the promises from the bicycle are far-reaching. Through it and the habits it will engender, we look for better and freer dress; for rounder limbs, fuller lung cavities, steadier nerves, and better developed muscles.

There are four demands before which the costume of the wheelwoman must pass in review: health, fitness, fashion and artistic beauty.

The third of these is ever at odds with the others. As for art in personal adornment, it can not be said to exist among people who tolerate a combination of sweaters, bloomers and leggings, or the deformed wheelwoman of alleged fashion journals. Yet the principle at the foundation of the dress question seems exceedingly simple. For play of the muscles, freedom is the first requisite, whether in cycling or scrubbing; and we must therefore instruct our patients to make certain modifications of their dress as necessary.

One has but to glance at ten riders of the hampered sex, to see nine who, ignorant of some of the rules of good riding, misapply force, waste effort, and run a certain risk of harm to themselves. The trouble is due chiefly to the lack of training, since the pupil in bicycling is turned adrift on the road as soon as she can balance a wheel or can mount and dismount one. Instruction should be insisted upon to obviate bad habits of riding; and unmerited criticism will thus be avoided.

It would be superfluous before an audience of physicians to do more than to name the ordinary precau. tions necessary for women who take up wheeling. 